\title{
Compensatie van misdrijfschade: veel beweging, voldoende inzicht en visie?
}

\author{
Verslag van het symposium van 24 september 2019
}

\author{
Mr.dr. M.R. Hebly en prof. mr. S.D. Lindenbergh*
}

\section{Inleiding}

In de afgelopen decennia is in toenemende mate ingezet op 'emancipatie' van slachtoffers van misdrijven. De aanleiding daarvoor moet niet worden gezocht in toenemende criminaliteit - daarvan lijkt immers geen sprake -, maar in het groeiende besef dat slachtoffers van misdrijven bijzondere aandacht verdienen. Op het punt van compensatie van hun schade zijn uiteenlopende maatregelen genomen vanuit de gedachte dat de dader moet vergoeden wat hij heeft veroorzaakt. Naar verschillende van die maatregelen is inmiddels ook (empirisch) onderzoek gedaan. De resultaten daarvan laten niet alleen verschillende vragen open, maar roepen ook nieuwe vragen op. Wie draagt uiteindelijk welke schade? Wat komt er daadwerkelijk van verhaal terecht? Wordt misdrijfschade met de daartoe beschikbare middelen efficiënt gecompenseerd? Kan het ook anders? Bestaan op deze punten voldoende inzicht en visie? Deze vragen stonden centraal tijdens het op 24 september 2019 aan de Erasmus Universiteit Rotterdam gehouden symposium 'Compensatie van misdrijfschade - solidariteit, verzekering, verhaal'. Het symposium werd georganiseerd door Erasmus School of Law in samenwerking met het Schadefonds Geweldsmisdrijven en gefaciliteerd door het Ministerie van Justitie en Veiligheid.

Het symposium was gericht op compensatie van individueel door een misdrijf geleden schade, niet op de meer algemene maatschappelijke kosten van misdrijven. ${ }^{1}$ Onder individuele schade door misdrijven is te verstaan letselschade in al zijn vormen (kosten van behandeling, revalidatie, verlies aan arbeidsvermogen, kosten van deskundigen, verhaal, derving van levensonderhoud, kosten van lijkbezorging en smartengeld), zaakschade, bijvoorbeeld door vernieling, inbraak en diefstal, en zuivere vermogensschade, bijvoorbeeld door oplichting en cybercriminaliteit. Voor wat betreft bronnen van compensatie

Mr. dr. M.R. Hebly is als universitair docent verbonden aan Erasmus School of Law. Prof. mr. S.D. Lindenbergh is als hoogleraar privaatrecht verbonden aan Erasmus School of Law.

1. Ook op algemeen niveau wordt geprobeerd misdrijfschade te kwantificeren. Zo wordt de 'maatschappelijke schade' in 2015 geschat op $€ 20,4$ miljard. Zie D.E.G. Moolenaar e.a., 'Kosten van criminaliteit', in: S.N. Kalidien (red.), Criminaliteit en rechtshandhaving 2016. Ontwikkelingen en samenhangen (Cahier 2017-12), Den Haag: WODC 2017, p. 101 e.v. kan worden gedacht aan eigen voorzieningen in de vorm van first party-verzekeringen (zorg-, reis-, inboedel-, rechtsbijstand-, arbeidsongeschiktheidsverzekering), aan overheidsvoorzieningen (algemene sociale zekerheid, Schadefonds Geweldsmisdrijven) en aan individueel verhaal op de dader naar de maatstaven van het civiele aansprakelijkheidsrecht.

\section{2. 'De dader betaalt', een uitdagend dogma}

Niemand kan het ermee oneens zijn: de dader moet vergoeden wat hij aan schade heeft veroorzaakt. Dit juridisch, politiek en moreel ijzersterke dogma stelt de praktijk evenwel voor substantiële problemen: in $67 \%$ tot $75 \%$ van de strafbare feiten is geen dader bekend. ${ }^{2}$ In die gevallen is individueel schadeverhaal op de dader hoe dan ook uitgesloten. En de verschillende stimuleringsmaatregelen uit de afgelopen jaren ten spijt: ook wanneer wel een dader bekend is, blijkt deze juist in de meest ernstige gevallen uiteindelijk hooguit een fractie van de schade te (kunnen) dragen. ${ }^{3}$ Het civiele proces, de klassieke verhaalsroute, wordt door slachtoffers van misdrijven nagenoeg niet gebruikt vanwege de (verwachte) hoge emotionele en financiële lasten en het uiteindelijke verhaalsrisico: onverzekerde, insolvabele daders. ${ }^{4}$ En wie voor het verhalen van zijn schade al toegang heeft tot een strafproces, wordt in dat verhaal weliswaar op uiteenlopende wijze gefaciliteerd (gefinancierde rechtsbijstand, versoepeld voegingscriterium, gegarandeerde betaling door de voorschotregeling (volledige 'dekking' bij gewelds- of zedenmisdrijven en tot $€ 5000$ bij andere misdrijven)), ${ }^{5}$ maar heeft ook daar een lange weg te gaan en

2. W.M. Schrama \& T. Geurts, Civiel schadeverhaal door slachtoffers van strafbare feiten. De rol van de civiele procedure: gebruik, knelpunten en oplossingsrichtingen, Den Haag: WODC 2012, p. 136.

3. J. Kuipers \& C. van Rij, Evaluatie voorschotregeling voor zeden-en geweldsmisdrijven en de daaraan gerelateerde inning m.b.t. schadevergoedingsmaatregelen, Den Haag: WODC 2018, p. 43 e.v.

4. Zie voor inschattingen van professionals Schrama \& Geurts 2012, p. 115 e.v. en voor ervaringen van verhaalzoekenden J.D.M. van Dongen, M.R. Hebly \& S.D. Lindenbergh, 'Je hebt geluk als je van een pauw mag plukken.' Ervaringen van slachtoffers van strafbare feiten met het verhalen van hun schade, Den Haag: WODC 2013, p. 22 e.v. en 40-42.

5. Wet van 17 december 2009 tot wijziging van het Wetboek van Strafvordering, het Wetboek van Strafrecht en de Wet schadefonds geweldsmisdrijven ter versterking van de positie van het slachtoffer in het strafproces (Stb. 2010, 1) en Uitvoeringsbesluit voorschotregeling Schadevergoedingsmaatregel (Stb. 2010,311). 
ziet uiteindelijk, zoals gezegd, weinig door de dader betaald worden. Ondertussen gaat verhaal via het strafproces wel met toenemende lasten gepaard: inspanningen van het slachtoffer, diens ondersteuning, openbaar ministerie, rechter en Centraal Justitieel Incassobureau (CJIB) alsmede overheidssubsidiëring door middel van de voorschotregeling. ${ }^{6}$

De in de afgelopen jaren genomen maatregelen ter bevordering van het verhaal van misdrijfschade en de empirische bevindingen daarover vormden aanleiding voor het Rotterdamse symposium. Tijdens het symposium werd het dogma 'de dader vergoedt de schade van het slachtoffer van zijn misdrijf ter discussie gesteld aan de hand van drie invalshoeken: solidariteit, verzekering en verhaal. Wat doet de overheid en wat moet zij doen als het gaat om compensatie van misdrijfschade? En waarom eigenlijk? En hoe verhoudt solidariteit zich tot compensatie en verhaal van schade? Welke rol speelt verzekering als het gaat om misdrijfschade? Welke mogelijkheden liggen hier? Wie draagt dan de lasten? Wat zijn daarvan de bezwaren? En hoe verloopt het schadeverhaal op de dader? Worden de juiste schades adequaat gecompenseerd? Leent het strafproces er zich voor of zijn er alternatieven? En is het reëel, en fair, dat de dader in het strafproces tot volledige vergoeding van schade wordt veroordeeld?

Aan de hand van een drietal workshops, die door rechters, advocaten, medewerkers van het Schadefonds Geweldsmisdrijven, medewerkers van Slachtofferhulp Nederland, wetenschappers en studenten werden gevolgd, werd op voornoemde vragen ingegaan.

\section{Solidariteit}

In de workshop over solidariteit werd ingegaan op de rol van en de investering door de overheid in compensatie en verhaal van misdrijfschade. ${ }^{7}$ Het gaat daarbij bijvoorbeeld om de tegemoetkomingen die het Schadefonds Geweldsmisdrijven verstrekt aan slachtoffers die geen verhaal op de dader kunnen nemen, maar ook om de facilitering van het schadeverhaal via het strafproces (gefinancierde rechtsbijstand, inspanningen van openbaar ministerie, rechter, CJIB) en de betalingen in het kader van de voorschotregeling.

Het Schadefonds Geweldsmisdrijven is het uit algemene middelen gefinancierde overheidsvangnet voor slachtoffers die door geweldsmisdrijven ernstig letsel hebben opgelopen en de daardoor geleden schade niet met succes op een ander (dader, verzekeraar) kunnen verhalen. Het fonds biedt tegemoetkomingen in de geleden schade aan de hand van categoriebedra-

6. Zie over de praktijk van behandeling van de vordering benadeelde partij uitvoerig R.S.B. Kool e.a., Civiel schadeverhaal via het strafproces. Een verkenning van de rechtspraktijk en regelgeving betreffende de voeging benadeelde partij, Utrecht: Utrecht Centre for Accountability and Liability Law 2016.

7. De workshop werd geleid door Gerdjan Hoekendijk, beleidsadviseur bij de afdeling Slachtofferbeleid van het Ministerie van Justitie en Veiligheid, coördinator op het terrein van schadevergoeding aan slachtoffers en bestuurder van het European Network on Victims' Rights, en Siewert Lindenbergh. gen, gerelateerd aan de ernst van het opgelopen letsel, tot een maximum van $€ 35.000$. Het Schadefonds Geweldsmisdrijven behandelt jaarlijks 8000 à 9000 aanvragen, waarvan ongeveer $70 \%$ wordt toegewezen, met een gemiddelde van ongeveer $€ 4000$ per tegemoetkoming. Het fonds keert jaarlijks ongeveer $€ 20$ miljoen uit, waarvan via het CJIB ongeveer $€ 1$ miljoen wordt verrekend met betalingen door daders. ${ }^{8}$

Een eerste vraag die op dit punt opkomt, is waarom de overheid ten aanzien van compensatie van misdrijfschade een bijzondere rol heeft. Het spreekt immers niet vanzelf dat de overheid zich individueel leed aantrekt. De visies op dit punt liepen uiteen, maar grondslagen voor overheidsverantwoordelijkheid op dit gebied werden gevonden in de gedachten dat misdrijfschade ernstiger is omdat een ander het heeft aangedaan, en dat de overheid een verantwoordelijkheid heeft omdat zij geen veiligheid heeft kunnen garanderen, en omdat zij door het verbod van afkoop van wrak het vervolgingsmonopolie naar zich toe heeft getrokken.

Omdat het bij solidariteit niet gaat om aansprakelijkheid van de overheid voor het ontstaan van de schade, ${ }^{9}$ rijst de vraag welke gevolgen de onderliggende grondslagen voor solidariteit hebben voor de omvang van te bieden compensatie. Anders dan bij aansprakelijkheid naar civielrechtelijke maatstaven, is het vanuit het perspectief van solidariteit immers niet vanzelfsprekend dat de geleden schade de maat vormt voor compensatie. Het ligt voor de hand dat bij uitingen op basis van solidariteit juist andere motieven, zoals erkenning of leniging van de ergste nood, de boventoon voeren. Die motieven leiden niet in dezelfde mate tot de gedachte van ongedaanmaking van schade zoals die zich aandringt bij foutaansprakelijkheid. Een illustratie daarvan vormt de voorziening van het Schadefonds Geweldsmisdrijven: het biedt tegemoetkomingen ter erkenning van het geleden leed naargelang de ernst van het letsel, maar met een maximum van $€ 35.000$ per slachtoffer. Dat bedrag zal de werkelijke schade in de ernstiger gevallen bij lange na niet dekken. Gelet op het uitkeringspatroon van het Schadefonds (8000 à 9000 aanvragen per jaar en een gemiddeld uitkeringsbedrag van $€ 4000$ ) lijkt het er overigens op dat het fonds vooral 'in de breedte' erkenning biedt en (lang) niet alleen in de meest ernstige gevallen.

Bezien vanuit het perspectief van solidariteit vormt de voorschotregeling, waarmee de overheid betaling van in het strafproces toegewezen vorderingen garandeert, ${ }^{10}$ een opmerkelijke figuur. Hier subsidieert de overheid immers veel selectiever.

8. Jaarverslag Schadefonds Geweldsmisdrijven 2018, http:// publicaties.schadefonds.nl/jaarverslag-schadefondsgeweldsmisdrijven-2018.

9. Die mogelijkheid bestaat onder omstandigheden natuurlijk ook, wanneer een overheidsorgaan onzorgvuldig handelt in civielrechtelijke zin. Vgl. recent HR 20 september 2019, ECLI:NL:HR:2019:1409, RvdW 2019/964 (Schietincident Alphen aan den Rijn).

10. Dat geldt voor schade door gewelds- en zedenmisdrijven geheel, en voor andere schades tot een maximum van $€ 5000$; proceskosten worden niet gedekt. 
Waar het Schadefonds Geweldsmisdrijven in beginsel toegankelijk is voor alle slachtoffers van geweldsmisdrijven met ernstig letsel, biedt de voorschotregeling alleen soelaas aan slachtoffers die een dader kunnen aanwijzen, die wordt vervolgd en wordt veroordeeld tot schadevergoeding. Dat zal, nu in $67 \%$ tot $75 \%$ van de strafbare feiten geen dader bekend is, in hooguit 33\% van de gevallen aan de orde zijn. Daar komt bij dat de voorschotregeling subsidieert op basis van volledige vergoeding van schade naar de maatstaven van het civiele aansprakelijkheidsrecht. En hoewel de gedachte is dat hetgeen op grond van de voorschotregeling wordt betaald op de dader wordt verhaald, blijkt dat laatste lang niet altijd te lukken, en in de gevallen van grote uitbetalingen zelfs nagenoeg niet. ${ }^{11}$ Dat is niet alleen een tamelijk hoge prijs voor het faciliteren van individueel verhaal door een selecte groep slachtoffers; het lijkt vanuit het perspectief van solidariteit ook atypisch om voor deze selecte groep volledige vergoeding te garanderen. Er zou nog wel wat voor te zeggen zijn als het hier typisch om de meest ernstig getroffenen zou gaan, maar juist hun vorderingen lijken (door de complexiteit van de aanspraak en de beperkingen van behandeling ervan in het strafproces) het slechtst door dit verhaalsproces te komen, terwijl ook juist in die gevallen van uiteindelijk verhaal op de dader het minst terechtkomt (zie par. 5). Het is dan ook de vraag of de huidige voorschotregeling vanuit het perspectief van solidariteit valt te rechtvaardigen.

Niet alleen op het punt van compensatie, maar ook op het punt van verhaal roept het perspectief van solidariteit eigen vragen op. Bij verhaal door de overheid kan worden gedacht aan verhaal door het CJIB van specifieke veroorzaakte schades, maar ook ontnemingsmaatregelen, boetes of een 'dadertaks' zouden kunnen worden gezien als verhaalsmaatregelen die ervoor zorgen dat - in een variant op verkeersaansprakelijkheid - 'criminal behavior pays it's way'.

De vraag is of solidariteit wel verhaal behoeft, en zo ja, welke vorm dan passend is. Juist bij al dan niet financiële inspanningen van de overheid ten behoeve van slachtoffers van misdrijven is denkbaar en verdedigbaar dat deze moeten worden gedaan ongeacht of de lasten ervan zich laten verhalen op de veroorzakers. Dat is immers bij (andere) vormen van sociale zekerheid ook het vertrekpunt. Voorts is de vraag of het vanuit het perspectief van solidariteit wel nodig is dat de voor een concreet slachtoffer gedane uitgaven worden verhaald op de concrete veroorzaker. Juist ten aanzien van de lasten van overheidsmaatregelen is immers denkbaar en verdedigbaar dat die worden verhaald op een breder publiek. Daarmee is niet gezegd dat individuele veroorzakers vrijuit mogen gaan, maar wel dat overheidsinspanningen ten behoeve van individuele slachtoffers naar aard en omvang niet afhankelijk hoeven te zijn van het verhaal op de individuele veroorzaker. Sterker: de rol van de overheid biedt juist bij uitstek mogelijkheden voor een bredere spreiding van de lasten over (mogelijke) veroorza-

11. Na zes jaar staat nog steeds $35 \%$ open en van de grotere schades zelfs 90\%. Zie Kuipers \& Van Rij 2018, p. 43-44. kers. Men denke aan ontnemingsmaatregelen die meer kunnen opleveren dan de in dat geval veroorzaakte schade of aan een dadertaks die over een grotere groep (potentiële) daders kan worden gespreid. Niettemin bleek tijdens de discussie in de workshop dat solidariteit ook op dit punt betekenis heeft: verkeersovertreders zouden niet moeten hoeven betalen voor gedrag van moordenaars. Daar staat tegenover dat er weinig bezwaar tegen lijkt om een zware crimineel ook te laten betalen voor misdrijfschade die hij niet zelf heeft veroorzaakt. Zo werd tijdens de discussie gesuggereerd om - bij wijze van 'poetic justice' - de opbrengsten van ontnemingsmaatregelen rechtstreeks ten behoeve van slachtoffers van misdrijven aan te wenden. Vooral vanuit maatschappelijk oogpunt lijkt deze op Robin Hood geïnspireerde aanpak aantrekkelijk.

\section{Verzekering}

Gelet op de beperkingen van het huidige verhaalsstelsel (grote schades komen er het slechtste af; insolventie van daders staat vaak aan compensatie en verhaal in de weg), stond in de workshop over verzekering de vraag centraal of verzekeringen op het gebied van misdrijfschade niet meer zouden kunnen betekenen. ${ }^{12}$ Verzekeringen hebben tot doel om lasten van individuen te spreiden over een grotere populatie. In die spreiding liggen mogelijkheden (de individuele veroorzaker of het individuele slachtoffer hoeft niet de volledige lasten te dragen), maar ook beperkingen (wie wil de lasten van misdrijven door verzekering dragen?). Verzekeringen bieden twee mogelijke vormen van spreiding: aansprakelijkheidsverzekeringen (third party-verzekeringen) spreiden de aansprakelijkheidslasten aan de zijde van veroorzakers; directe verzekeringen (first party-verzekeringen) spreiden de lasten aan de zijde van benadeelden.

Waar aansprakelijkheid voor schade op veel maatschappelijke terreinen (verkeersongevallen, arbeidsongevallen, medische fouten) door aansprakelijkheidsverzekeringen wordt gedragen, is dat op het gebied van misdrijven juist niet het geval. Niet alleen speelt hier het eerder gesignaleerde probleem dat slechts in een kwart van de gevallen een dader bekend is, zodat alleen in die gevallen individueel verhaal kan worden gezocht. Ook in de gevallen waarin de benadeelde er wel in slaagt een dader aan te wijzen, is verzekeringsdekking allerminst vanzelfsprekend. Hoewel de verzekeringsdichtheid voor aansprakelijkheid ook buiten verkeer en bedrijfsmatige activiteiten (zeer) groot is - vrijwel iedereen beschikt onverplicht over een aansprakelijkheidsverzekering voor particulieren (AVP) -, beogen de bestaande verzekeringen juist aansprakelijkheid voor opzettelijk gedrag, en dus voor misdrijven, uit te slui-

12. De workshop werd geleid door Arlette Schijns, advocaat bij Beer advocaten te Amsterdam en onderzoeker bij het Amsterdam Centre for Comprehensive Law van de Vrije Universiteit Amsterdam, en Louis Visscher, hoogleraar Legal Economic Analysis of Tort and Damages aan Erasmus School of Law. 
ten. ${ }^{13}$ Dat wordt hier te lande voor AVP's als vanzelfsprekend aanvaard, maar andere verzekeringen (verplichte aansprakelijkheidsverzekering motorrijtuigen) en andere jurisdicties laten zien dat het ook anders kan: uitsluiting van het opzetverweer jegens de benadeelde, maar verhaal op de dader door de verzekeraar. $^{14}$ Bedenkingen tegen een dergelijk stelsel zijn - behalve dat het alleen soelaas biedt bij een bekende dader, of er zou al een waarborgfonds aan moeten worden toegevoegd dat juist daders zich mogelijk niet tegen aansprakelijkheid hebben verzekerd, en dat de premies (en dus de lasten van alsdan verzekerd crimineel gedrag) dan worden gedragen door alle verzekerden. (Ook) hier lijkt dus solidariteit, maar dan onder verzekerden, een beletsel. Denkbaar is bovendien dat dekking van misdrijfschade leidt tot hogere premies, en dat dit weer leidt tot een lagere verzekeringsdichtheid ('averechtse selectie'), hetgeen niet alleen gevolgen heeft voor verzekering tegen misdrijfschade, maar juist voor alle schadeveroorzakingen die een AVP beoogt te verzekeren.

Verzekering aan de zijde van de benadeelde (first party) heeft in ieder geval als voordeel dat uitkering kan geschieden, ongeacht of er sprake is van een misdrijf. Veel schade door misdrijven wordt inmiddels op dergelijke wijze gedekt, door bijvoorbeeld zorgverzekering, inboedelverzekering of arbeidsongeschiktheidsverzekering. Dergelijke verzekeringen dekken evenwel niet specifiek schade door misdrijven, het afsluiten ervan is deels afhankelijk van het initiatief van de benadeelde en laatstgenoemde betaalt er ook zelf voor.

\section{Verhaal}

De workshop over verhaal stond voornamelijk in het teken van het functioneren van het materiële aansprakelijkheidsrecht in de strafprocessuele context. ${ }^{15}$ De afgelopen jaren is beleidsmatig sterk ingezet op versterking van de (rechts)positie van slachtoffers van strafbare feiten, onder meer in het licht van de Europese richtlijn minimumnormen slachtoffers. ${ }^{16}$ De overheid draagt de verantwoordelijkheid slachtoffers de mogelijkheid te bieden hun schade op de dader te verhalen, sinds het EU-kaderbesluit uit 2001 ook binnen de kaders van het strafproces. ${ }^{17}$ Deelnemers aan de workshop reageerden vanuit verschillende achtergronden (beleid, advocatuur, rechtspraak, slachtofferhulp enzovoort) en dikwijls op grond van eigen praktijkervaring in de strafrechtsketen.

13. Zie over de (complexe) finesses van de mate waarin zij daarin slagen $H R$ 13 april 2018, ECLI:NL:HR:2018:601, NJ 2018/463, m.nt. S.D. Lindenbergh (Shaken baby).

14. Zie uitvoerig A.J.J.G. Schijns, Naar een verzekerd slachtofferrecht. Effectief schadeverhaal van slachtoffers van misdrijven via het private verzekeringsrecht, Amsterdam: ACCL 2017, p. 187-233.

15. De workshop over verhaal werd geleid door Renée Kool, universitair hoofddocent straf(proces)recht bij het Utrecht Centre for Accountability and Liability Law (UCALL) en het Willem Pompe Instituut (Universiteit Utrecht), en Marnix Hebly.

16. Richtlijn $2012 / 29 / \mathrm{EU}$ van 25 oktober 2012 tot vaststelling van minimumnormen voor de rechten, de ondersteuning en de bescherming van slachtoffers van strafbare feiten, en ter vervanging van Kaderbesluit 2001/220/JBZ.

17. Kaderbesluit 2001/220/JBZ.
Een deel van de discussie richtte zich op het aspect van 'vergemakkelijking'. Voor slachtoffers zijn de wegen tot schadevergoeding na een misdrijf moeilijk te overzien; er zou sprake zijn van een terrein dat vraagt om vereenvoudiging. ${ }^{18}$ Maar ook onder professionals lijkt die wens te bestaan, in het bijzonder in het licht van de - uiteindelijk - beperkte ruimte die het strafproces biedt en de beperkte civielrechtelijke kennis bij de betrokkenen in de strafrechtsketen om een vordering naar civiel aansprakelijkheidsrecht te beoordelen. Daarbij is opgemerkt dat rechtbanken op dit punt verschillend beleid voeren, en het dus voor betrokkenen uitmaakt in welk arrondissement zij 'zitten'. Aan deelnemers van de workshops is de stelling voorgehouden dat het huidige materiële aansprakelijkheids- en schadevergoedingsrecht te complex is voor afdoening in het strafproces, en dat het bestaan van de voorschotregeling als solidariteitsinstrument vereenvoudiging/veralgemening rechtvaardigt, bijvoorbeeld in de vorm van normering van vergoedingen, met behoud van recht op 'het meerdere' bij de civiele rechter. ${ }^{19}$ Denkbaar is dat notoir ingewikkelde schadeposten (verlies van arbeidsvermogen, toekomstige kosten voor hulp en zorg, enzovoort) in het strafproces worden vergoed door toewijzing van categoriebedragen, die weliswaar niet rechtstreeks zijn gebaseerd op de in concreto geleden schade, maar waarover dan ook minder discussie hoeft te worden gevoerd. Daartegen is het bezwaar geuit dat met een dergelijke normering het uitgangspunt van volledigheid van de vergoeding in het gedrang komt, terwijl het de civielrechtelijke verhouding tussen partijen is die zo veel mogelijk moet worden verwezenlijkt. De vraag is evenwel of het uitgangspunt van volledigheid niet al structureel onder druk staat door de dynamiek van de ontvankelijkheid: voor zover de behandeling van de schadevergoedingsaanspraak een onevenredige belasting van het strafgeding vormt, verklaart de rechter zich niet-ontvankelijk, wat betekent dat het slachtoffer aangewezen is op de 'gewone' civielrechtelijke route (wat dikwijls niet leidt tot daadwerkelijk verhaal). Het bestaan van de voorschotregeling - de overheid 'springt ertussen' wanneer de dader niet tijdig en/of geheel betaalt - zou ook kunnen rechtvaardigen dat slachtoffers (iets) minder dan een volledige schadevergoeding ontvangen. De algemene tevredenheid met de maatregelen die de afgelopen jaren zijn doorgevoerd, lijkt daar bovendien bij aan te sluiten: naar maatstaven van het civiele recht zal het 'niet de schoonheidsprijs' verdienen wat er in het strafproces gebeurt, maar het wordt als positief gezien dat het slachtoffer in elk geval 'iets' krijgt, althans veel meer dan voorheen mogelijk was.

De inspanningen die in de strafprocessuele sfeer worden verricht, raken - zoals gezegd - niet de grootste categorie van slachtoffers voor wie geen dader in beeld is. Tijdens de workshops is benadrukt dat de grootste groep slachtoffers te maken

18. Ministerie van Veiligheid en Justitie, Recht doen aan slachtoffers (visiedocument), 2013, p. 19.

19. Een vergelijkbare vereenvoudiging is doorgevoerd bij het Schadefonds, dat van een schadepostenbenadering overstapte op toekenning van 'allinbedragen'. 
heeft met een onbekende dader, en dat bij een bekende dader 'succesvol voegen' ook nog geen zekerheid is. De vraag is wat het wezenlijke verschil is tussen slachtoffers met een bekende maar insolvente dader en slachtoffers die vanwege een onbekende dader met lege handen blijven staan. Voor de eerste categorie trekt de overheid immers een 'diepere portemonnee' (via de voorschotregeling) dan voor de tweede categorie (die moet terugvallen op het Schadefonds). Dat verschil lijkt moeilijk te rechtvaardigen, maar kan alleen maar toenemen naarmate het strafproces meer ruimte zou gaan bieden voor schadeverhaal (bijvoorbeeld met een 'klapluikmechanisme') ten gunste van de vordering benadeelde partij, en overigens ook wanneer zou worden ingezet op versterking van de mogelijkheden tot schadeverhaal via de civiele rechter. Een mogelijkheid om (extreme) ongelijkheid te voorkomen zou kunnen zijn om de voorschotregeling te maximeren, ook voor gevallen van gewelds- en zedenmisdrijven, bijvoorbeeld tot een bedrag van $€ 100.000 .{ }^{20}$ Wat daarmee aan overheidsuitgaven wordt bespaard, zou via ophoging van de bedragen van het Schadefonds wellicht 'eerlijker' kunnen worden verdeeld onder hen die zwaar zijn getroffen door criminaliteit, dat wil zeggen: los van de vraag of in het concrete geval wel of geen dader in beeld is.

De discussies tijdens de workshops leerden overigens dat het niet altijd eenvoudig is om het schadeverhaal via het strafproces te evalueren zonder te differentiëren naar aspecten die in concrete zaken beslissend kunnen zijn. Gaat het bijvoorbeeld om aanspraken van een kleinere omvang (bedragen van enkele duizenden euro's, 'bulkzaken'), dan lijkt het materiële aansprakelijkheidsrecht in de strafprocessuele context redelijk goed te 'werken': de dader betaalt uiteindelijk wel wat hij heeft aangericht, ${ }^{21}$ het slachtoffer krijgt zijn schade betrekkelijk snel vergoed, en de overheid faciliteert een en ander via het CJIB. Vooral bij schades van een grotere omvang lijkt het civiele aansprakelijkheidsrecht niet effectief en wordt het beroep op overheidssolidariteit sterker. Dat betekent dat de omvang van de schadevergoeding een bepalende factor is: hoe omvangrijker het bedrag, des te groter de kans dat de dader het niet (volledig) kan betalen. Tegelijkertijd wordt vanuit de praktijk benadrukt dat niet zozeer die omvang bepalend is voor de kans op 'succes' in het strafproces, maar veeleer de relatieve belastendheid voor het strafgeding, die samenhangt met de ingewikkeldheid ervan. Dat zou verklaren waarom bijvoorbeeld in mensenhandelzaken soms zeer omvangrijke bedragen worden toegewezen: het strafdossier zou in dergelijke gevallen vaak zodanig inzicht geven in de bedragen die met de uitbuiting waren gemoeid, dat de vordering van het slachtoffer betrekkelijk eenvoudig kan worden beoordeeld. Voor vorderingen tot

20. Daarmee zouden in elk geval de 'extreme uitschieters' kunnen worden voorkomen. Denk bijv. aan de Afghaanse vluchteling die in augustus 2018 twee willekeurige Amerikaanse toeristen neerstak op Amsterdam Centraal en die in het strafproces werd veroordeeld tot betaling van een schadevergoeding van bijna $€ 3$ miljoen. Zie Rb. Amsterdam 14 oktober 2019, ECLI:NL:RBAMS:2019:7566.

21. Betrekkelijk kleine bedragen zijn voor veroordeelden uiteindelijk nog wel op te brengen, zo valt af te leiden uit Kuipers \& Van Rij 2018, p. 43 e.v. vergoeding van (toekomstig) verlies van arbeidsvermogen wegens door een misdrijf toegebracht letsel ligt dat anders: die vorderingen kunnen in omvang geringer zijn dan mensenhandelclaims, maar vergen dikwijls uitvoeriger debat en onderbouwing. Vorderingen tot vergoeding van immateriële schade worden gezien als relatief eenvoudig: zij vragen niet om ingewikkelde bewijslevering en kunnen bovendien in betrekkelijk korte tijd worden vastgesteld in verband met de 'normerende werking' van de smartengeldbundel.

\section{Bevindingen}

Het morele dogma - de individuele dader vergoedt het individuele slachtoffer - is in de praktijk eigenlijk een dwaalspoor gebleken. Waar het kan, moet het natuurlijk worden nagestreefd. De onmogelijkheden ervan moeten niettemin in kaart worden gebracht en onder ogen worden gezien. Op dit punt dient aldus te worden geïnvesteerd in inzicht in het functioneren van de huidige constellatie. Mogelijk vragen die inzichten ook om een herijking van het bestaande stelsel van compensatie en verhaal: aan de grenzen van de haalbaarheid van individueel verhaal op de dader rijzen - in het bijzonder in de sfeer van de misdrijfschade - onvermijdelijke kwesties van maatschappelijke solidariteit en verzekeringssolidariteit. Dat vraagt om een brede(re) visie op de problematiek. 